\title{
Interaction of Amorphous Silica Nanoparticles with Erythrocytes in Vitro: Role of Oxidative Stress
}

\author{
Abderrahim Nemmar Sumaya Beegam ${ }^{\mathrm{a}}$ Priya Yuvaraju ${ }^{\mathrm{a}}$ Javed Yasin ${ }^{\mathrm{b}}$ \\ Allen Shahin ${ }^{c}$ Badreldin H. Alid \\ aDepartment of Physiology, College of Medicine and Health Sciences, ${ }^{b}$ Department of Internal Medicine, \\ College of Medicine and Health Sciences, 'Department of Microbiology, College of Medicine and \\ Health Sciences, Al Ain, United Arab Emirates University, dDepartment of Pharmacology and Clinical \\ Pharmacy, College of Medicine \& Health Sciences, Sultan Qaboos University, Muscat, Al-Khod, \\ Sultanate of Oman
}

\section{Key Words}

Silica nanoparticles $\bullet$ Erythrocytes $\bullet$ Oxidative stress $\bullet$ Hemolysis

\begin{abstract}
Background/Aims: The use of engineered nanomaterials in the form of nanoparticles (NP) for various biomedical applications, as well as in consumer products, has raised concerns about their safety for human health. These NP are intended to be administered directly into the circulation following intravenous injection, or they may reach the circulation following other routes of administration such as oral or inhalation, and interact with circulating cells such as erythrocytes. However, little is known about the interaction of amorphous SiNP with erythrocytes. Methods: We studied the interaction of amorphous silica nanoparticles (SiNP) at various concentrations $(1,5,25$ and $125 \mu \mathrm{g} / \mathrm{ml})$ with mouse erythrocytes in vitro. Results: Incubation of erythrocytes with SiNP caused a dose-dependent hemolytic effect. Likewise, the activity of lactate dehydrogenase was dose-dependently increased by SiNP. Transmission electron microscopy analysis revealed that SiNP are taken up by erythrocytes. Lipid erythrocyte susceptibility to in vitro peroxidation measured by malondialdehyde showed a significant and dose-dependent increase in erythrocytes. SiNP also enhanced the antioxidant activities of superoxide dismutase (SOD), catalase and reduced glutathione (GSH). Moreover, SiNP increased caspase 3, triggered annexin $\mathrm{V}$-binding and caused a dose-dependent increase of cytosolic calcium concentration. Conclusion: It can be concluded that SiNP cause a dosedependent hemolytic activity and are taken up by the erythrocytes. We also found that SiNP induce the occurrence of oxidative activity, apoptosis and increase cytosolic $\mathrm{Ca}^{2+}$, which may explain their haemolytic activity. Our in vitro data suggest that SiNP may, plausibly, lead to anemia and circulatory disorders in vivo.
\end{abstract}

Copyright @ 2014 S. Karger AG, Basel

Prof. A. Nemmar

Department of Physiology, Faculty of Medicine and Health Sciences

United Arab Emirates University, P.O. Box 17666, Al Ain, (United Arab Emirates)

Tel. +971-37137533, Fax +971 37671966

E-Mail anemmar@uaeu.ac.ae,E-Mail anemmar@hotmail.com 


\section{Introduction}

Nanotechnology is an evolving science with the potential to manufacture and use engineered nanomaterials in the nanometer range $(<100 \mathrm{~nm})$ [1-3]. Nanoparticles (NP) have unique physicochemical properties, such as small size, large surface area to mass ratio, high reactivity, high carrier capacity and easy variation of surface properties [1-3]. They are being widely studied in various medical areas such as drug delivery, molecular diagnostics and gene therapy [1-3].

Amorphous silica nanoparticles (SiNP) are widely used in a variety of industries [3]. They are used as additives to cosmetics, drugs and food [3]. Moreover, they are currently tested for different medical applications, for instance drug delivery, cancer therapy and DNA transfection [3].

With medical applications, the intravenously injected SiNP can be distributed in the bloodstream, and cause the release of pharmacologically-active agents to targeted cells [3]. However, at the same time, NP can directly interact with circulatory cells such as erythrocytes, leukocytes or platelets and potentially induce undesirable toxicity [4-7]. Therefore, investigation of the direct impact of SiNP on erythrocytes is needed, and will help to understand the possible pathophysiological effects of those particles on erythrocytes.

It has been reported that exposure to particulate air pollution causes a decrease in erythrocyte antioxidant enzyme activity [8]. A decrease in erythrocytes in association with exposure to either particulate air pollution or nanoparticles in humans and experimental animals has been reported [9-11]. More recently, we showed that diesel exhaust particles (DEP) caused dose- and species-dependent erythrocyte hemolysis and oxidative stress [12].

Exposure of human platelets in vitro to amorphous SiNP induces oxidative effects leading to platelet aggregation [13]. We recently showed that intraperitoneal administration of SiNP causes proinflammatory and procoagulant responses in vivo and in vitro [14]. However, little is known about the interaction of amorphous SiNP with erythrocytes. It has only been demonstrated that SiNP cause hemolysis $[15,16]$.

The aim of this in vitro study was five-fold: (1) to evaluate the hemolytic activity of four graded doses of SiNP on mouse erythrocytes; (2) to assess the effect of SiNP on lactate dehydrogenase release by erythrocytes; (3) to evaluate whether SiNP are taken up by erythrocytes; (4) to appraise erythrocyte oxidant/antioxidant status following exposure to SiNP, including malondialdehyde (MDA), catalase, superoxide dismutase (SOD) and reduced glutathione (GSH) levels; and (5) to assess the effects of SiNP on erythrocytes cytosolic calcium concentration, annexin $\mathrm{V}$ and caspase 3.

\section{Materials and Methods}

Amorphous silica nanoparticles

Amorphous silica nanoparticles (50 nm) were purchased from Polysciences (Warrington, PA, USA). Their characteristics were recently studied $[13,17]$. As indicated by the supplier (Polysciences, Warrington, PA, USA), the commercially available negative surface-charged silica nanoparticles used in our studies were amorphous solid (nonporous) pure silicon dioxide synthesized by a precipitation process. Using the same type of SiNP from the same source, Corbalan et al. $[13,17]$ confirmed the size stated by the supplier and found that the zeta potential of the silica nanoparticles was more negative than $-30 \mathrm{mV}$.

\section{Blood Collection}

This project was reviewed and approved by our Institutional Review Board, and experiments were performed in accordance with protocols approved by the Institutional Animal Care and Research Advisory Committee.

TO mice (30-35 g, HsdOla:TO, Harlan, UK) were housed in light (12-h light:12-h dark cycle) and temperature-controlled $\left(22 \pm 1^{\circ} \mathrm{C}\right)$ rooms. They had free access to commercial laboratory chow and were provided tap water ad libitum. For blood collection, the animals were anesthetized intraperitoneally with sodium pentobarbital ( $45 \mathrm{mg} / \mathrm{kg}$ ), and then blood was drawn from the inferior vena cava in EDTA (4\%). 


\section{Hemolysis experiments}

The hemolysis experiment has been performed according to a previously described method $[12,18]$. Mouse blood was mixed separately by gentle inversion of the tube and centrifuged at $1,200 \times g$ for $10 \mathrm{~min}$. The plasma supernatant was discarded and the erythrocytes were washed 4 times by suspending them in saline $(0.9 \%)$ before centrifugation at $1,200 \times g$ for $10 \mathrm{~min}$. The final suspension consisted of $5 \%$ by volume erythrocyte in saline. Flat-bottomed 12 -well plates were used. To each well, $900 \mu \mathrm{l}$ of erythrocyte suspension was added in duplicate. One hundred $\mu \mathrm{l}$ SiNP suspensions $(1,5,25$ and $125 \mu \mathrm{g} / \mathrm{ml})$ were added, and mixed gently by pipetting. Negative control wells consisted of normal saline ( $\mathrm{NaCl} 0.9 \%$ ) containing Tween 80 $(0.01 \%)$, and positive control wells consisted of $0.1 \%$ Triton-X 100 . The plates were then positioned in an MS 3 digital microtiter shaker (IKA WERKE GmbH \& CO, Staufer, Germany) and rotated at $300 \mathrm{rpm}$ for $30 \mathrm{~min}$ at room temperature. After that, the samples were transferred into $1.5 \mathrm{ml}$ eppendorf tubes, and were centrifuged for $5 \mathrm{~min}$. Finally, $90 \mu \mathrm{l}$ were carefully removed from each tube and transferred to a clean plate. The amount of hemoglobin released into the supernatant was determined spectrophotometrically at a wavelength of $540 \mathrm{~nm}$. The percent hemolysis was calculated using the equation of a straight line, $y=m x+c$, where $\%$ hemolysis $(x)=$ [optical density $(y)$ - negative control optical density $(c)] /[($ positive control optical density - negative control optical density)/100] $(m)[12,18]$.

\section{Erythrocytes analysis by transmission electron microscopy (TEM)}

In separate animals, to assess whether SiNP are internalized by erythrocytes, mouse erythrocytes were incubated for $30 \mathrm{~min}$ with either saline containing Tween $80(0.01 \%)$ or SiNP, as described above. The samples were then collected and fixed in Karnovski's fixative. Fixed cells were later rinsed in $0.1 \mathrm{M}$ phosphate buffer, dehydrated in a graded series of ethanol concentrations, post-fixed in $1 \% \mathrm{OsO}_{4}$ in $0.1 \mathrm{M}$ cacodylate buffer for $1 \mathrm{~h}$, and embedded in Araldite. Ultrathin sections were obtained, stained with uranyl acetate and lead citrate, and examined by transmission electron microscopy [19, 20].

\section{Measurement of LDH and markers of oxidative stress}

Nine hundred $\mu$ l of the erythrocyte suspension was incubated with SiNP $(100 \mu \mathrm{l})$ at final concentrations of 1, 5, 25 and $125 \mu \mathrm{g} / \mathrm{ml}$, in a 12-well plate. The erythrocytes treated with normal saline ( $\mathrm{NaCl} 0.9 \%$ ) containing Tween $80(0.01 \%)$ were taken as control. The plate was positioned in an MS 3 digital microtiter shaker (IKA WERKE GmbH \& CO, Staufer, Germany) and rotated at $300 \mathrm{rpm}$ for $30 \mathrm{~min}$ at room temperature. At the end of the incubation period, the cell suspensions were centrifuged, and aliquots of the resulting supernatants were subjected to LDH assay and markers of oxidative stress. LDH activities were determined using standard clinical laboratory methods. Erythrocytes malondialdehyde (MDA) was quantified colorimetrically following its controlled reaction with thiobarbituric acid [21] with a commercially available kit (Cayman Chemicals, Ann Arbor, MI, USA). SOD activity (Cayman Chemicals, Ann Arbor, MI, USA), reduced GSH concentration (Sigma Chemicals, St. Louis, MO), and catalase activity (Cayman Chemicals, Ann Arbor, MI, USA) were analyzed spectrophotometrically according to methods described by the manufacturers.

\section{Measurement of intracellular $\mathrm{Ca}^{2+}$}

Intracellular $\mathrm{Ca}^{2+}$ was measured after incubation with either vehicle or various concentrations of SiNP, as described above, according to a previously described technique [22]. Briefly, erythrocytes were washed in Ringer solution and then centrifuged for $5 \mathrm{~min}$ at $1,200 \times \mathrm{g}$. The erythrocyte pellets were resuspended with $2 \mathrm{ml}$ of $5 \mathrm{mM}$ Ringer and then added with $2 \mu \mathrm{M}$ of fura 2AM (Calbiochem; La Jolla, CA). The cells were then incubated at $37^{\circ} \mathrm{C}$ for $15 \mathrm{~min}$. After that, the cell suspension was centrifuged for 5 min at 1,200 $\times g$. The fura 2AM-loaded erythrocytes were resuspended in $2 \mathrm{ml}$ Ringer solution containing $1 \mathrm{mM} \mathrm{CaCl}$, and incubated $30 \mathrm{~min}$ in dark. Finally, $\mathrm{Ca}^{2+}$-dependent fluorescence intensity was then monitored with a fluorometer (model SFM 25, Kontron; Zurich, Switzerland) set at 340-nm excitation and 510-nm emission [23].

Caspase-3 activity assay

The activity of caspase-3 was determined using a Caspase- 3 activity colorimetric assay kit according to the manufacturer's instruction (Invitrogen, MD, USA). 
Fig. 1. Hemolytic action of silica nanoparticle (SiNP) in the incubation medium of erythrocytes isolated from the blood of mice. The results are expressed as $\%$ of positive control ( $0.1 \%$ Triton-X 100). Data are mean \pm SEM ( $n=6$ in each group). Statistical analysis by one-way ANOVA followed by Dunnett's multiple range tests.

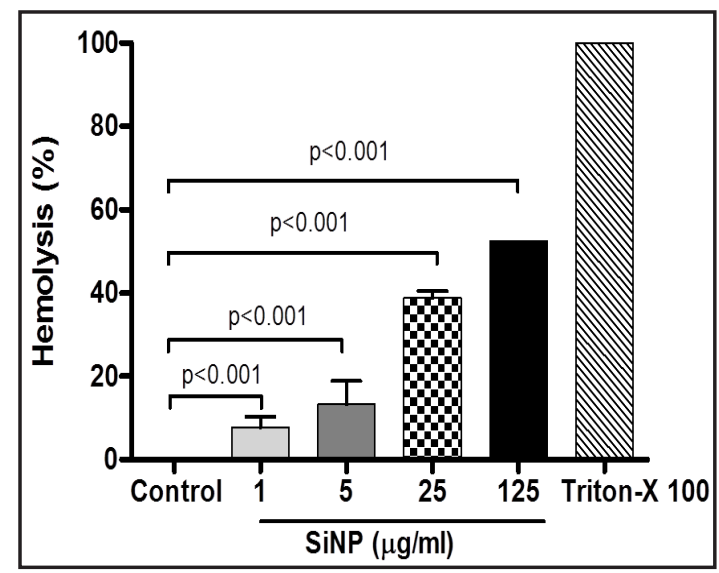

Fluorescence-activated cell sorter (FACS) analysis of annexin V-binding

Cell membrane phospholipid scrambling with subsequent exposure of phosphatidylserine at the cell surface was estimated from binding of fluorescent annexin V- fluorescein isothiocyanate (FITC). The preparation of samples for FACS analysis was performed according to a recently described method [24]. Annexin V-FITC was determined according to the manufacturer's instruction (BD Pharmingen, San Jose, CA, USA) using FITC annexin V apoptosis detection kit I.

Statistics

All statistical analyses were performed with GraphPad Prism Software version 5 (San Diego, CA, USA). To determine whether parameters were normally distributed, the Kolmogorov-Smirnov statistic normality test was applied. Comparisons between groups were performed by one way analysis of variance (ANOVA), followed by Dunnett's multiple range tests. LDH data, which were not normally distributed, were analyzed with the Kruskal-Wallis test followed by Dunn's multiple comparison test. $P$-values $<0.05$ were considered as significant. All the data in the figures were reported as mean \pm SEM.

\section{Results}

Effect of SiNP on erythrocytes hemolysis

Incubation of erythrocytes with SiNP caused significant and dose dependent hemolytic effects (Fig. 1). The degree of hemolysis observed was $8 \%(1 \mu \mathrm{g} / \mathrm{ml} \mathrm{SiNP}), 13 \%(5 \mu \mathrm{g} / \mathrm{ml}$

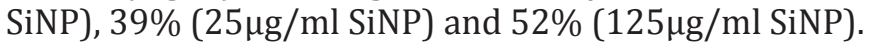

\section{Erythrocytes analysis by electron microscopy}

Figure 2 illustrates the TEM analysis in control (A) and SiNP (B-H) exposed erythrocytes. The incubation of erythrocytes with SiNP (1-125 $\mu \mathrm{g} / \mathrm{ml})$ for 30 min revealed the presence of particles either around or within the erythrocytes (Fig. 1B-H).

\section{Effect of SiNP on LDH activity}

Figure 3 illustrates the effect of SiNP on the activity of LDH in mouse erythrocyte suspensions. LDH was used as a marker of erythrocytes damage. The incubation of erythrocytes with SiNP showed a dose-dependent increase in LDH activity. The effect was significant at $25(P<0.01)$ and $125 \mu \mathrm{g} / \mathrm{ml}$ SiNP $(P<0.0001)$.

\section{Effect of SiNP on concentrations of MDA and GSH and activities of catalase and SOD}

Figure 4A represents the effect of DEP on the concentrations of MDA in mouse erythrocyte suspensions. MDA was used to assess the proneness of erythrocytes lipid to in vitro peroxidation. The incubation of erythrocytes with SiNP showed a significant and dosedependent increase in MDA concentrations (Fig. 4A). The effect was statistically significant at $25 \mu \mathrm{g} / \mathrm{ml}(P<0.0001)$ and $125 \mu \mathrm{g} / \mathrm{ml}(P<0.0001)$. 


\begin{tabular}{|c|c|c|}
\hline Cellular Physiology & Cell Physiol Biochem 2014;34:255-265 & \\
\hline and Biochemistry & $\begin{array}{l}\text { DOI: 10.1159/000362996 } \\
\text { Publisned onIIne: July uz, } 2014\end{array}$ & $\begin{array}{l}\text { O 2014 S. Karger AG, Basel } \\
\text { www.karger.com/cpb }\end{array}$ \\
\hline
\end{tabular}

Fig. 2. Transmission electron micrographs (TEM) of erythrocytes after in vitro incubation with saline containing either $0.01 \%$ of Tween 80 (A) or silica nanoparticles (SiNP) $1 \mu \mathrm{g} / \mathrm{ml}$ (B), $5 \mu \mathrm{g} / \mathrm{ml}$ (C and D), $25 \mu \mathrm{g} / \mathrm{ml}$ ( $\mathrm{E}$ and F) and $125 \mu \mathrm{g} / \mathrm{ml}$ (G and $\mathrm{H}$ ). The presence of SiNP either outside or within the erythrocytes is indicated by arrows. Scale bars in A, B, C, E and G: $2 \mu \mathrm{m}$. Scale bars in $\mathrm{D}, \mathrm{F}$ and $\mathrm{H}$ : $1 \mu \mathrm{m}$.

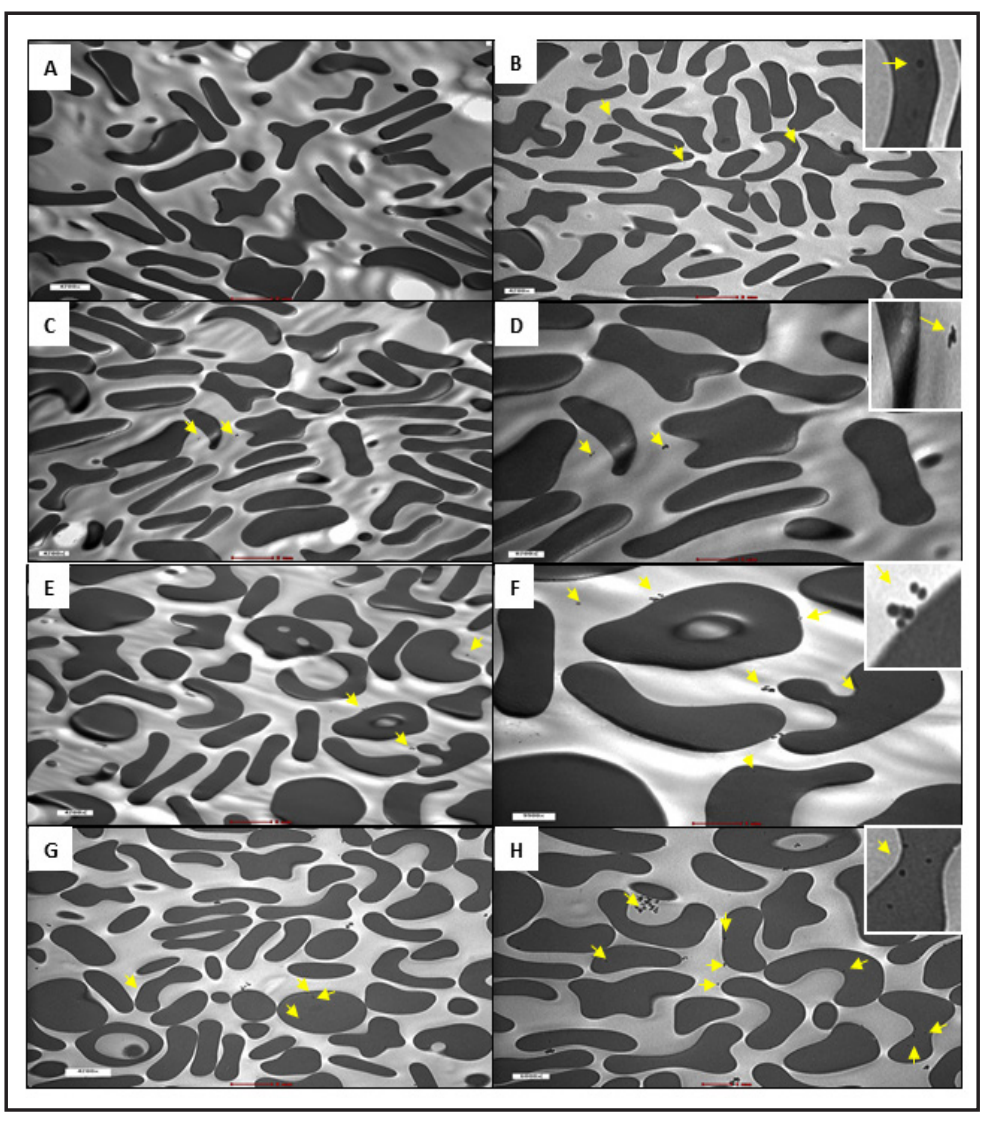

Fig. 3. Effect of silica nanoparticles (SiNP) on lactate dehydrogenase (LDH) activity measured in the incubation medium of erythrocytes. Data are mean \pm SEM ( $n=6$ in each group). Statistical analysis by Kruskal-Wallis test followed by Dunn's multiple comparison test.

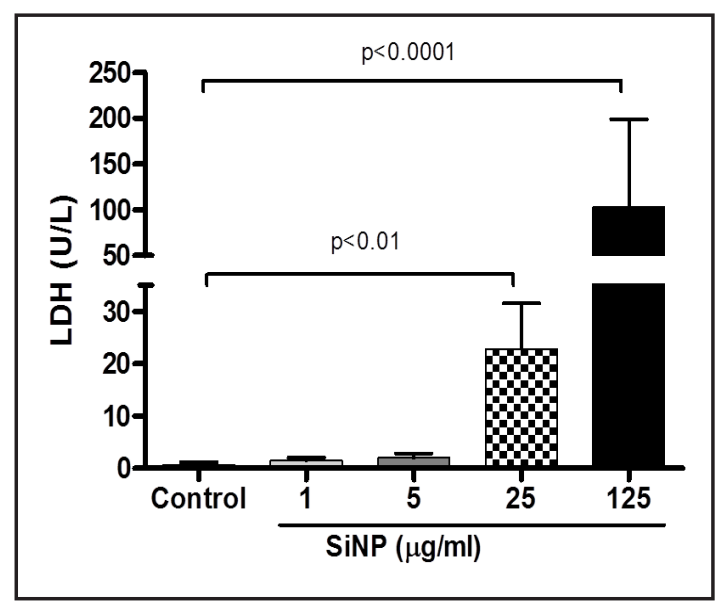

Figure 4B shows the effect of SiNP on the concentration of GSH. Compared with the control group, the concentration of GSH in erythrocytes was significantly and dosedependently increased. The level of significance was achieved at all the studied SiNP doses, i.e. $1 \mu \mathrm{g} / \mathrm{ml}(P<0.05), 5 \mu \mathrm{g} / \mathrm{ml}(P<0.0001), 25 \mu \mathrm{g} / \mathrm{ml}(P<0.0001)$ and $125 \mu \mathrm{g} / \mathrm{ml}(P<0.0001)$. Likewise, compared with the control group, a significant increase of catalase activity was seen following the incubation of erythrocytes with $5 \mu \mathrm{g} / \mathrm{ml}(P<0.05), 25 \mu \mathrm{g} / \mathrm{ml}(P<0.0001)$ and $125 \mu \mathrm{g} / \mathrm{ml}(P<0.0001)$ SiNP (Fig. 4C). Figure 4D illustrates the effect of SiNP on erythrocyte SOD activity. Incubation of erythrocytes with SiNP induced a dose-dependent increase of SOD, and the plateau/maximum effect was achieved at a $25 \mu \mathrm{g} / \mathrm{ml}$ dose. The effects were significant at all the studied doses, i.e. $1 \mu \mathrm{g} / \mathrm{ml}(P<0.05), 5 \mu \mathrm{g} / \mathrm{ml}(P<0.0001), 25 \mu \mathrm{g} / \mathrm{ml}$ $(P<0.0001)$ and $125 \mu \mathrm{g} / \mathrm{ml}(P<0.0001)$. 

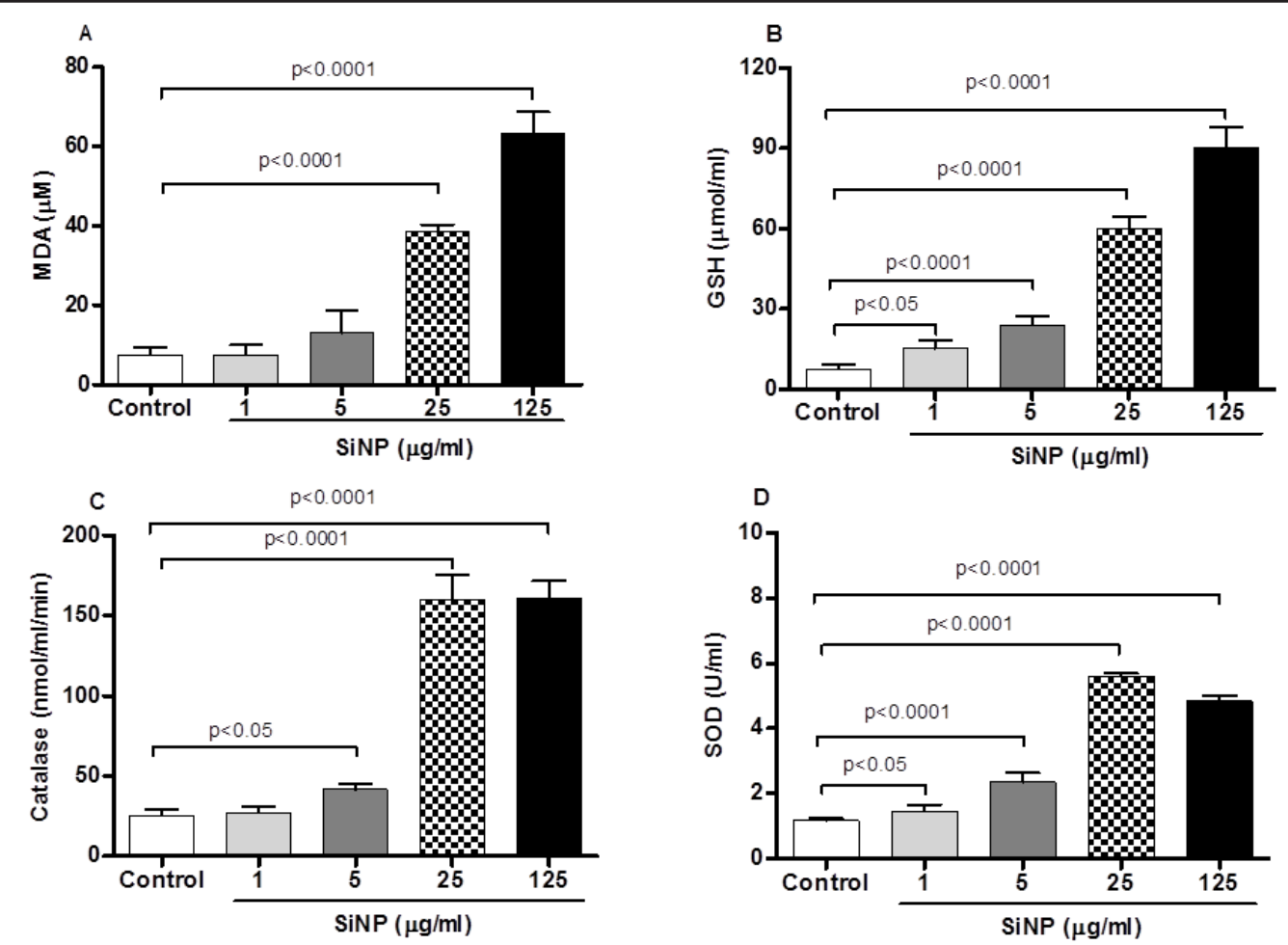

Fig. 4. Effect of of silica nanoparticles (SiNP) on the concentrations of malondialdehyde (MDA, A) and reduced glutathione (GSH, B), and activities of catalase (C) and superoxide dismutase (SOD, D) measured in the incubation medium of erythrocytes. Data are mean \pm SEM ( $n=6$ in each group). Statistical analysis by one-way ANOVA followed by Dunnett's multiple range tests.

Fig. 5. Effect of silica nanoparticles (SiNP) on caspase 3 activity measured in the incubation medium of erythrocytes. Data are mean \pm SEM ( $n=6$ in each group). Statistical analysis by one-way ANOVA followed by Dunnett's multiple range tests.

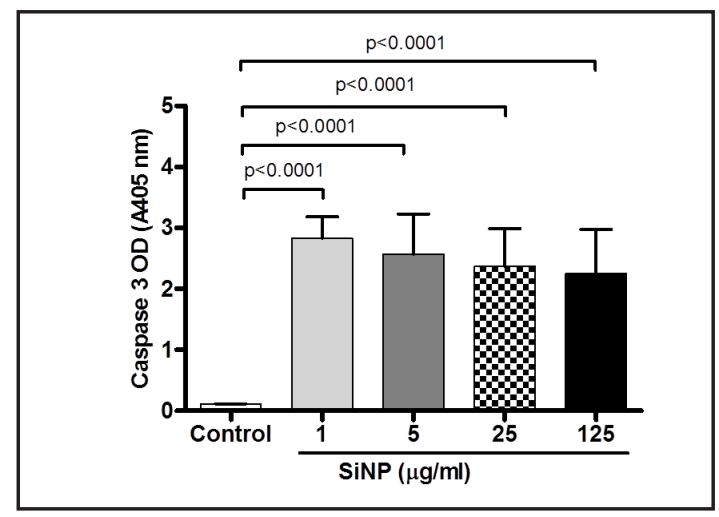

Effect of SiNP on caspase 3 activity

The effect of SiNP on erythrocyte caspase 3 activity is represented in Figure 5. Compared with the control group, the incubation of erythrocytes with SiNP caused a significant increase of caspase 3 activity at all the studied doses $(P<0.0001)$. The maximum effect was already observed at $1 \mu \mathrm{g} / \mathrm{ml} \mathrm{SiNP}$, and the effects were comparable between the various doses studied $(1 \mu \mathrm{g} / \mathrm{ml}-125 \mu \mathrm{g} / \mathrm{ml})$.

\section{Effect of SINP on annexin V-binding}

Exposure of phosphatidylserine at the cell surface was estimated from binding of fluorescent annexin V- FITC. Incubation of erythrocytes with SiNP triggered annexin V-binding (Fig. 6). The effect was significant at all the studied doses, i.e. $1 \mu \mathrm{g} / \mathrm{ml}(P<0.005)$, $5 \mu \mathrm{g} / \mathrm{ml}(P<0.05), 25 \mu \mathrm{g} / \mathrm{ml}(P<0.0001)$ and $125 \mu \mathrm{g} / \mathrm{ml}(P<0.005)$. 


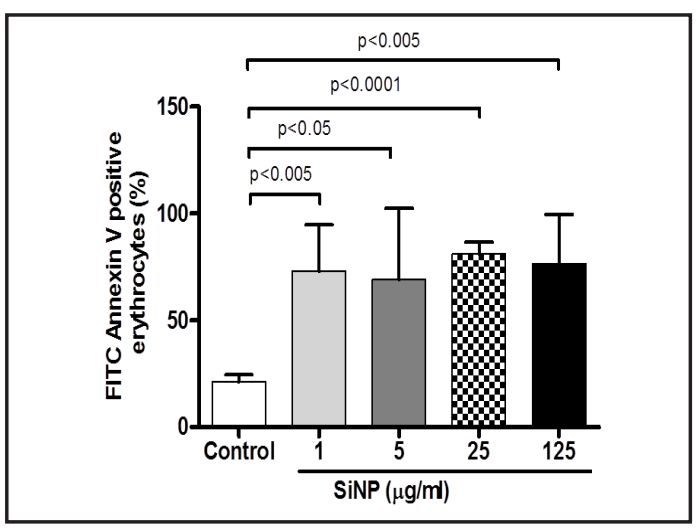

Fig. 6. The quantification of the FACS analysis of the apoptotic annexin V-fluorescein isothiocyanate (FITC) positive erythrocytes following the incubation with SiNP. FITC-annexin $\mathrm{V}$ binding to erythrocytes is given as a percentage of annexin $\mathrm{V}$-positive cells. Data are mean \pm SEM ( $n=3-5$ in each group). Statistical analysis by one-way ANOVA followed by Dunnett's multiple range tests.

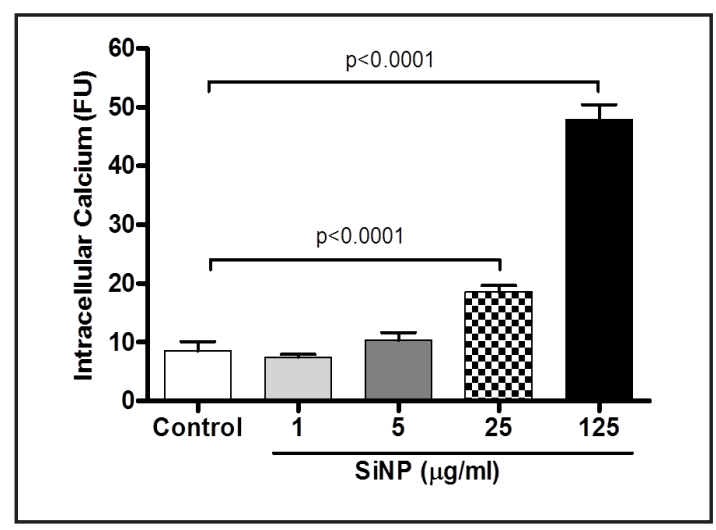

Fig. 7. Effect of silica nanoparticles (SiNP) on cytosolic calcium concentration from Fluo3 fluorescence measured in the incubation medium of erythrocytes. Data are mean \pm SEM ( $n=6$ in each group). Statistical analysis by one-way ANOVA followed by Dunnett's multiple range tests.

\section{Effect of SiNP on intracellular calcium}

Figure 7 illustrates the effect of SiNP on cytosolic calcium concentration from Fluo3 fluorescence. Compared with the control group, the incubation of erythrocytes with SiNP caused a significant increase in cytosolic calcium concentration. The level of significance was achieved at $25 \mu \mathrm{g} / \mathrm{ml}(P<0.0001)$ and $125 \mu \mathrm{g} / \mathrm{ml}(P<0.0001)$.

\section{Discussion}

In this work, we show that SiNP are able to penetrate erythrocytes, and induce oxidative stress, apoptosis and increase cytosolic $\mathrm{Ca}^{2+}$ leading to hemolysis.

Several studies have reported that NP may have unpredicted biological effects compared with larger particles [1,3]. It has been reported in human endothelial cells that monodispersed $\mathrm{SiO}_{2}-\mathrm{NP}$ caused cytotoxic cell damage and decreased cell survival in a concentration-dependent manner [25]. $\mathrm{SiO}_{2}-\mathrm{NP}$ with sizes of 14, 15, and $16 \mathrm{~nm}$ exhibited higher toxicity as compared with larger $\mathrm{SiO}_{2}$-NP of 104 and $335 \mathrm{~nm}$ [25]. We have recently demonstrated that amorphous SiNP cause systemic inflammation, coagulation events and alter vascular reactivity. The effects observed with $50 \mathrm{~nm}$ SiNP were more pronounced than those with $500 \mathrm{~nm}$ SiNP [14].

The use of nanoparticles can happen via different routes such as skin penetration, ingestion and inhalation. It has been previously reported that SiNP could penetrate the skin and enter various tissues [26]. Even after inhalation, nanoparticles have been reported to rapidly translocate to the systemic circulation and reach different organs $[4,5,27,28]$. Moreover, with medical applications, following injection, nanoparticles can be distributed by the bloodstream and affect vascular homeostasis [3]. Therefore, studies on the interaction of nanoparticles with erythrocytes are essential.

In vivo studies in mice using intravenously injected SiNP reported doses of 29.5-177.5 $\mathrm{mg} / \mathrm{kg}$ [29] and 10-30 mg/kg [30]. For a $25 \mathrm{~g}$ mouse, this would correspond to 737-4437 $\mu \mathrm{g}$ and 250-750 $\mu \mathrm{g}$, respectively. The approximate blood volume of a mouse is $77-80 \mu \mathrm{l} / \mathrm{g}$, and for a $25 \mathrm{~g}$ mouse this is equivalent to $1.9-2.0 \mathrm{ml}$. Therefore, we assume that the concentration of intravenously injected SiNP in blood would be 368-2,218 $\mu \mathrm{g} / \mathrm{ml}[29]$ and $125-375 \mu \mathrm{g} / \mathrm{ml}$ 
[30], respectively. The SiNP concentrations that we used here were 1, 5, 25 and $125 \mu \mathrm{g} / \mathrm{ml}$ in a final suspension consisting of $5 \%$ erythrocytes. The hematocrit measured after blood collection in mice was on average $35 \%$. Thus, by taking into account the dilution factor (i.e. 7), we assume that SiNP concentrations used would be 7, 35, 175 and $875 \mu \mathrm{g} / \mathrm{ml}$ in a final suspension consisting of $35 \%$ of erythrocytes. Regarding human exposure scenario (e.g. nanomedicine), pharmacokinetic data related to the liposome-encapsulated doxorubicin nanoparticles, used in cancer therapy, established plasma concentrations of more than $10 \mu \mathrm{g} / \mathrm{ml}$ [31]. Therefore, at least one concentration used in our in vitro study is probably relevant to mice and human exposures.

Our data show that SiNP caused a significant and dose-dependent hemolytic activity. Our findings corroborate recent studies which reported that SiNP induce hemolysis [15, 16]. We have recently reported that DEP caused dose- and species-dependent erythrocyte hemolysis [12]. Moreover, a direct hemolytic effect of $\mathrm{TiO}_{2}$ nanoparticles has been previously reported in rabbit erythrocytes [32]. In the present study, LDH activity was used as a marker of erythrocytes damage and hemolysis. In line with the hemolysis findings, LDH activity was significantly and dose-dependently increased following the incubation with SiNP.

In the present study, because of the observed hemolytic effect of SiNP, we also wanted to verify whether and to what extent SiNP can penetrate the erythrocytes. To this end, we performed TEM analysis of erythrocytes following the incubation with SiNP. Our data show the presence of SiNP within the erythrocytes. We have recently reported that DEP are taken up by erythrocytes [12]. Following inhalation, $\mathrm{TiO}_{2}$ nanoparticles were localized within blood capillaries and erythrocytes [33]. In addition, $100 \mathrm{~nm}$ MCM-41-type mesoporous silica nanoparticles were found to adsorb to the surface of erythrocytes [34].

It is well-established that SiNP cause hemolysis $[15,16]$. Nevertheless, the mechanism related to this effect is poorly understood. In the current study, we assessed the effect of SiNP on the biomarkers of oxidative stress, including MDA, GSH, SOD and catalase. Following the occurrence of oxidative stress, erythrocyte membranes are susceptible to lipid peroxidation that involves cleavage of polyunsaturated fatty acids at their double bonds leading to the formation of aldehydes, MDA, and 4-hydroxynonenal [21]. These derivative substances may modify the structural and functional integrity of cells [21]. The measurement of MDA is customarily used as a method for the quantification of lipid peroxidation [21]. Our data corroborate the hemolysis findings; erythrocytes incubated with SiNP exhibited a significant and dose-dependent increase in MDA. This suggests that SiNP induced oxidative stress to the erythrocyte; the plasma membrane is often the initial site of damage, and the resulting peroxidation of membrane lipids causes hemolysis and cross-links between protein and lipid molecules to different extents [35]. We have recently reported that incubation of erythrocytes with DEP $(1-100 \mu \mathrm{g} / \mathrm{ml})$ caused a significant and dose-dependent increase in MDA in erythrocytes of rats, but not humans or mice [12]. The last finding was explained by the fact that human and mouse erythrocytes are resistant to peroxidation of membrane lipids. The results of the present study shows a significant effect at 25 and $125 \mu \mathrm{g} / \mathrm{ml} \mathrm{SiNP}$; such an effect was absent in our previous study using mouse erythrocytes incubated with up to $100 \mu \mathrm{g} / \mathrm{ml}$ DEP [12], suggesting that the pro-oxidant potency of engineered SiNP is higher than that of pollutant DEP.

Erythrocytes contain intracellular antioxidant enzymes such as SOD, catalase and GSH, that work together to prevent oxidative damage to the cell [35]. SOD catalyzes the conversion of superoxide radicals to hydrogen peroxide, while catalase converts hydrogen peroxide into water [35]. GSH is a sensitive biomarker of cell functionality and viability, and is implicated in the cellular defence against hydroperoxides and free radicals [35]. Our data show a significant and dose dependent increase in SOD and catalase activities, and GSH concentrations. This indicates that the development of oxidative stress induced by SiNP is accompanied by an adaptive response that counterbalances the potentially damaging activity of oxygen free radicals by antioxidant defence mechanisms. We have reported an increase of antioxidant in various organs, including the lungs, heart liver and kidney following short-term exposure to cigarette smoke [36, 37]. 
Caspases are aspartate-specific cysteine proteinases that exist as latent zymogens, but once activated by apoptotic signals, they promote apoptosis. Caspase 3 is synthesized as a 32 $\mathrm{kDa}$ zymogen that is processed to mature $20 / 17 \mathrm{kDa}$ and $12 \mathrm{kDa}$ subunits by cleavage at Asp9, Asp28 and Asp175 [38]. It is well established that erythrocytes express caspases [38, 39]. In the present study, we found that incubation of erythrocytes with SiNP stimulates caspase 3. In apoptotic cells, the membrane phospholipid phosphatidylserine is translocated from the inner to the outer leaflet of the plasma membrane, thereby exposing phosphatidylserine to the external cellular environment [40]. Annexin $\mathrm{V}$ is $\mathrm{a} \mathrm{Ca}_{2}{ }^{+}$dependent phospholipid-binding protein that has a high affinity for phosphatidylserine, and binds to cells with exposed PS [40]. Our data show that exposure of erythrocytes to SiNP triggered annexin V-binding. This finding corroborates the increase of caspase 3 and confirms the occurrence of apoptosis following the exposure to SiNP. The last could be the consequence of the oxidative stress induced by SiNP. Indeed, it has been previously reported that caspases are activated by oxidative stress [41].

Erythrocytes do not have nuclei and mitochondria, which are crucial components in the apoptotic process. Despite that, it has been shown that exposure of erythrocytes to the $\mathrm{Ca}^{2+}$ ionophore ionomycin causes cell shrinkage, membrane blebbing and phosphatidylserine exposure, all typical features of apoptotic nucleated cells [40]. Our data show a significant increase in erythrocyte cytosolic calcium activity following incubation with SiNP. It has been reported that eryptosis (suicidal erythrocyte death) could be triggered by increased calcium activity, and that calcium may enter through non-selective cation channels which can be activated by oxidative stress $[40,42,43]$. Thus, we can speculate that the increase in oxidative stress caused by SiNP may have induced an increase in cytosolic calcium and subsequent erythrocyte death. Additional studies are required to clarify this issue.

It can be concluded that SiNP cause a dose-dependent hemolytic activity and are taken up by the erythrocytes. We also found that SiNP induce oxidative activity and apoptosis, and increase cytosolic $\mathrm{Ca}^{2+}$, which may explain the hemolysis induced by these nanoparticles. Surface modification/functionalization, and protein corona need in-depth evaluations. Recently, It has been shown that protein corona can significantly modify the responses to biomedical nanoparticles It would be of interest, in our future experiments to investigate further the role of oxidative stress by using antioxidants and that of calcium using calcium chelators.

\section{Acknowledgements}

The authors would like to thank Saeed Tariq for his technical help with EM pictures.

This work was supported by the funds of the United Arab Emirates University (UAEU), College of Medicine and Health Sciences and United Arab Emirates University individual grant and UAEU-Sultan Qaboos University grant.

\section{Disclosure Statement}

No conflicts of interest to disclose.

\section{References}

1 Nemmar A, Holme JA, Rosas I, Schwarze PE, Alfaro-Moreno E: Recent advances in particulate matter and nanoparticle toxicology: a review of the in vivo and in vitro studies. Biomed Res Int 2013;2013:279371.

2 Oberdorster G, Oberdorster E, Oberdorster J: Nanotoxicology: An emerging discipline evolving from studies of ultrafine particles. Environ Health Perspect 2005;113:823-839. 
3 Napierska D, Thomassen LC, Lison D, Martens JA, Hoet PH: The nanosilica hazard: another variable entity. Part Fibre Toxicol 2010;7:39.

-4 Nemmar A, Hoet PH, Vanquickenborne B, Dinsdale D, Thomeer M, Hoylaerts MF, Vanbilloen H, Mortelmans L, Nemery B: Passage of inhaled particles into the blood circulation in humans. Circulation 2002;105:411414.

5 Nemmar A, Vanbilloen H, Hoylaerts MF, Hoet PH, Verbruggen A, Nemery B: Passage of intratracheally instilled ultrafine particles from the lung into the systemic circulation in hamster. Am J Respir Crit Care Med 2001;164:1665-1668.

6 Shimada A, Kawamura N, Okajima M, Kaewamatawong T, Inoue H, Morita T: Translocation pathway of the intratracheally instilled ultrafine particles from the lung into the blood circulation in the mouse. Toxicol Pathol 2006;34:949-957.

7 Vermylen J, Nemmar A, Nemery B, Hoylaerts MF: Ambient air pollution and acute myocardial infarction. J Thromb Haemost 2005;3:1955-1961.

8 Delfino RJ, Staimer N, Tjoa T, Gillen DL, Polidori A, Arhami M, Kleinman MT, Vaziri ND, Longhurst J, Sioutas C: Air pollution exposures and circulating biomarkers of effect in a susceptible population: clues to potential causal component mixtures and mechanisms. Environ Health Perspect 2009;117:1232-1238.

-9 Seaton A, Soutar A, Crawford V, Elton R, McNerlan S, Cherrie J, Watt M, Agius R, Stout R: Particulate air pollution and the blood. Thorax 1999;54:1027-1032.

10 Ruckerl R, Phipps RP, Schneider A, Frampton M, Cyrys J, Oberdorster G, Wichmann HE, Peters A: Ultrafine particles and platelet activation in patients with coronary heart disease - results from a prospective panel study. Part Fibre Toxicol 2007;4:1.

11 Nemmar A, Inuwa IM: Diesel exhaust particles in blood trigger systemic and pulmonary morphological alterations. Toxicology Letters 2008;176:20-30.

$>12$ Nemmar A, Zia S, Subramaniyan D, Al-Amri I, Al Kindi MA, Ali BH: Interaction of diesel exhaust particles with human, rat and mouse erythrocytes in vitro. Cell Physiol Biochem 2012;29:163-170.

13 Corbalan JJ, Medina C, Jacoby A, Malinski T, Radomski MW: Amorphous silica nanoparticles aggregate human platelets: potential implications for vascular homeostasis. Int J Nanomedicine 2012;7:631-639.

14 Nemmar A, Albarwani S, Beegam S, Yuvaraju P, Yasin J, Attoub S, Ali BH: Amorphous silica nanoparticles impair vascular homeostasis and induce systemic inflammation . Int J Nanomedicine 2014;9:2779-2789.

15 Rabolli V, Thomassen LC, Princen C, Napierska D, Gonzalez L, Kirsch-Volders M, Hoet PH, Huaux F, Kirschhock CE, Martens JA, Lison D: Influence of size, surface area and microporosity on the in vitro cytotoxic activity of amorphous silica nanoparticles in different cell types. Nanotoxicology 2010;4:307-318.

16 Zhang H, Dunphy DR, Jiang X, Meng H, Sun B, Tarn D, Xue M, Wang X, Lin S, Ji Z, Li R, Garcia FL, Yang J, Kirk ML, Xia T, Zink JI, Nel A, Brinker CJ: Processing pathway dependence of amorphous silica nanoparticle toxicity: colloidal vs pyrolytic. J Am Chem Soc 2012;134:15790-15804.

$\checkmark 17$ Corbalan JJ, Medina C, Jacoby A, Malinski T, Radomski MW: Amorphous silica nanoparticles trigger nitric oxide/peroxynitrite imbalance in human endothelial cells: inflammatory and cytotoxic effects. Int J Nanomedicine 2011;6:2821-2835.

18 Lu SL, Duffin R, Poland C, Daly P, Murphy F, Drost E, MacNee W, Stone V, Donaldson K: Efficacy of simple short-term in vitro assays for predicting the potential of metal oxide nanoparticles to cause pulmonary inflammation. Environ Health Perspect 2009;117:241-247.

19 Nemmar A, Hoylaerts MF, Hoet PHM, Dinsdale D, Smith T, Xu H, Vermylen J, Nemery B: Ultrafine particles affect experimental thrombosis in an in vivo hamster model. Am J Respir Crit Care Med 2002;166:9981004.

20 Nemmar A, Al Maskari S, Ali BH, Al Amri IS: Cardiovascular and lung inflammatory effects induced by systemically administered diesel exhaust particles in rats. Am J Physiol Lung Cell Mol Physiol 2007;292:L664-L670.

21 Lefevre G, Beljean-Leymarie M, Beyerle F, Bonnefont-Rousselot D, Cristol JP, Therond P, Torreilles J: Evaluation of lipid peroxidation by assaying the thiobarbituric acid-reactive substances. Annales de Biologie Clinique 1998;56:305-319.

22 Foller M, Mahmud H, Gu S, Wang K, Floride E, Kucherenko Y, Luik S, Laufer S, Lang F: Participation of leukotriene C(4) in the regulation of suicidal erythrocyte death. J Physiol Pharmacol 2009;60:135-143. 
23 Pignatelli P, Lenti L, Sanguigni V, Frati G, Simeoni I, Gazzaniga PP, Pulcinelli FM, Violi F: Carnitine inhibits arachidonic acid turnover, platelet function, and oxidative stress. Am J Physiol Heart Circ Physiol 2003;284:H41-H48.

24 Jilani K, Qadri SM, Lang F: Geldanamycin-induced phosphatidylserine translocation in the erythrocyte membrane. Cell Physiol Biochem 2013;32:1600-1609.

25 Napierska D, Quarck R, Thomassen LC, Lison D, Martens JA, Delcroix M, Nemery B, Hoet PH: Amorphous silica nanoparticles promote monocyte adhesion to human endothelial cells: size-dependent effect. Small 2013;9:430-438.

-26 Nabeshi H, Yoshikawa T, Matsuyama K, Nakazato Y, Matsuo K, Arimori A, Isobe M, Tochigi S, Kondoh S, Hirai T, Akase T, Yamashita T, Yamashita K, Yoshida T, Nagano K, Abe Y, Yoshioka Y, Kamada H, Imazawa T, Itoh N, Nakagawa S, Mayumi T, Tsunoda S, Tsutsumi Y: Systemic distribution, nuclear entry and cytotoxicity of amorphous nanosilica following topical application. Biomaterials 2011;32:2713-2724.

-27 Pery AR, Brochot C, Hoet PH, Nemmar A, Bois FY: Development of a physiologically based kinetic model for 99m-Technetium-labelled carbon nanoparticles inhaled by humans. Inhal Toxicol 2009;21:1099-1107.

28 Oberdorster G, Sharp Z, Atudorei V, Elder A, Gelein R, Lunts A, Kreyling W, Cox C: Extrapulmonary translocation of ultrafine carbon particle following whole-body inhalation exposure of rats. J Toxicol Environ Health A 2002; 65:1531-1543.

29 Yu Y, Li Y, Wang W, Jin M, Du Z, Li Y, Duan J, Yu Y, Sun Z: Acute toxicity of amorphous silica nanoparticles in intravenously exposed ICR mice. PLoS One 2013;8:e61346.

-30 Nishimori H, Kondoh M, Isoda K, Tsunoda S, Tsutsumi Y, Yagi K: Histological analysis of 70-nm silica particles-induced chronic toxicity in mice. Eur J Pharm Biopharm 2009;72:626-629.

-31 Gabizon A, Isacson R, Libson E, Kaufman B, Uziely B, Catane R, Ben-Dor CG, Rabello E, Cass Y, Peretz T, .: Clinical studies of liposome-encapsulated doxorubicin. Acta Oncol 1994;33:779-786.

-32 Li SQ, Zhu RR, Zhu H, Xue M, Sun XY, Yao SD, Wang SL: Nanotoxicity of TiO(2) nanoparticles to erythrocyte in vitro. Food and Chemical Toxicology 2008;46:3626-3631.

-33 Geiser M, Rothen-Rutishauser B, Kapp N, Schurch S, Kreyling W, Schulz H, Semmler M, Hof VI, Heyder J, Gehr P: Ultrafine particles cross cellular membranes by nonphagocytic mechanisms in lungs and in cultured cells. Environ Health Perspect 2005;113:1555-1560.

34 Zhao YN, Sun XX, Zhang GN, Trewyn BG, Slowing II, Lin VSY: Interaction of mesoporous silica nanoparticles with human red blood cell membranes: Size and surface functionality effects. Abstracts of Papers of the American Chemical Society 2011;241.

35 Reddy CSSS, Subramanyam MVV, Vani R, Devi SA: In vitro models of oxidative stress in rat erythrocytes: Effect of antioxidant supplements. Toxicology in Vitro 2007;21:1355-1364.

-36 Nemmar A, Raza H, Subramaniyan D, John A, Elwasila M, Ali BH, Adeghate E: Evaluation of the pulmonary effects of short-term nose-only cigarette smoke exposure in mice. Exp Biol Med (Maywood) 2012;237:1449-1456.

-37 Nemmar A, Raza H, Subramaniyan D, Yasin J, John A, Ali BH, Kazzam EE: Short-term systemic effects of nose-only cigarette smoke exposure in mice: role of oxidative stress. Cell Physiol Biochem 2013;31:15-24.

-38 Mandal D, Moitra PK, Saha S, Basu J: Caspase 3 regulates phosphatidylserine externalization and phagocytosis of oxidatively stressed erythrocytes. FEBS Lett 2002;513:184-188.

39 Bratosin D, Estaquier J, Petit F, Arnoult D, Quatannens B, Tissier JP, Slomianny C, Sartiaux C, Alonso C, Huart JJ, Montreuil J, Ameisen JC: Programmed cell death in mature erythrocytes: a model for investigating death effector pathways operating in the absence of mitochondria. Cell Death Differ 2001;8:1143-1156.

40 Foller M, Huber SM, Lang F: Erythrocyte programmed cell death. IUBMB Life 2008;60:661-668.

41 Matarrese P, Straface E, Pietraforte D, Gambardella L, Vona R, Maccaglia A, Minetti M, Malorni W: Peroxynitrite induces senescence and apoptosis of red blood cells through the activation of aspartyl and cysteinyl proteases. FASEB J 2005;19:416-418.

42 Kaestner L, Tabellion W, Lipp P, Bernhardt I: Prostaglandin E2 activates channel-mediated calcium entry in human erythrocytes: an indication for a blood clot formation supporting process. Thromb Haemost 2004;92:1269-1272.

-43 Duranton C, Huber SM, Lang F: Oxidation induces a Cl(-)-dependent cation conductance in human red blood cells. J Physiol 2002;539:847-855. 